\title{
Partitioning of catchment water budget and its implications for ecosystem carbon exchange
}

\author{
D. Lee ${ }^{1}$, J. Kim ${ }^{1,2}$, K.-S. Lee ${ }^{3}$, and S. Kim ${ }^{4}$ \\ ${ }^{1}$ Global Environment Laboratory, Dept. of Atmospheric Sciences, Yonsei Univ., Seoul 120-749, Korea \\ ${ }^{2}$ Global Center of Excellence for Sustainable Urban Regeneration, Institute of Industrial Science, The University of Tokyo, \\ Tokyo 153-8505, Japan \\ ${ }^{3}$ Korea Basic Science Institute and Graduate School of Analytical Science and Technology, Daejon, 305-333, Korea \\ ${ }^{4}$ Korea Institute of Construction Technology (Sustainable Water Resource Research Center), Goyang, 411-712, Korea
}

Received: 31 August 2009 - Published in Biogeosciences Discuss.: 4 December 2009

Revised: 27 April 2010 - Accepted: 13 May 2010 - Published: 14 June 2010

\begin{abstract}
Spatially averaged annual carbon budget is one of the key information needed to understand ecosystem response and feedback to climate change. Water availability is a primary constraint of carbon uptake in many ecosystems and therefore the estimation of ecosystem water use may serve as an alternative to quantify Gross Primary Productivity $(G P P)$. To examine this concept, we estimated a long-term steady state water budget for the Han River basin $\left(\sim 26000 \mathrm{~km}^{2}\right)$ in Korea and examined its application for catchment scale carbon exchange. For this, the catchment scale evapotranspiration $(E T)$ was derived from the long term precipitation $(P)$ and discharge $(Q)$ data. Then, using stable isotope data of $P$ and $Q$ along with other hydrometeorological information, $E T$ was partitioned into evaporation from soil and water surfaces $\left(E_{S}\right)$, evaporation from intercepted rainfall $\left(E_{I}\right)$, and transpiration $(T)$. $E_{S}$ was identified as a minor component of $E T$ in the study areas regardless of the catchment scales. The annual $T$, estimated from $E T$ after accounting for $E_{I}$ and $E_{S}$ for the Han River basin from 1966 to 2007 , was $22 \sim 31 \%$ of annual $P$ and the proportion decreased with increasing $P$. Assuming that $T$ further constrains the catchment scale GPP in terms of water use efficiency (WUE), we examined the possibility of using $T$ as a relative measure for the strength and temporal changes of carbon uptake capacity. The proposed relationship would provide a simple and practical way to assess the spatial dis-
\end{abstract}

Correspondence to: D. Lee (dlee@ieg.or.kr) tribution of ecosystem GPP, provided the WUE estimates in terms of $G P P / T$ at ecosystem scale could be obtained. For carbon and water tracking toward a sustainable Asia, ascertaining such a spatiotemporally representative WUE and their variability is a requisite facing the flux measurement and modeling communities.

\section{Introduction}

The catchment water cycle, assuming a steady state, consists of precipitation $(P)$, discharge $(Q)$, and evapotranspiration $(E T)$. $E T$ comprises of water cycle components that occur via disparate bio-physical processes such as evaporation from soil/water surfaces $\left(E_{S}\right)$, evaporation from intercepted rainfalls $\left(E_{I}\right)$ and transpiration from the intercellular space of leaves through stomata $(T)$. The necessity of $E T$ partitioning into its components can be well emphasized in attempts to better understand energy and mass exchanges between the atmosphere and the land surface (e.g., Choudhury et al., 1998). In particular, the transpiration occurs simultaneously with $\mathrm{CO}_{2}$ uptake during photosynthesis, which signifies a mechanistic inter-dependency between water and carbon exchanges in terrestrial ecosystems (e.g., Nobel, 1999). Therefore, $E T$ partitioning and improved understanding of the water cycle have practical applications for issues related to climate change such as water resource management and the quantitative assessment of carbon uptake capacity of terrestrial ecosystems (e.g., Choudhury, 2000).

Published by Copernicus Publications on behalf of the European Geosciences Union. 
The water resource management in Korea has been a challenging task mainly due to extremely uneven seasonal distribution of precipitation associated with the monsoon climate. The seasonally recurring flood and drought are common and often disastrous (WAMIS, http://www.wamis.go.kr). Furthermore, hydro-geological characteristics such as high ratio of runoff to precipitation and short residence time of water become additional obstacles for the secure water supply planning in the country (e.g., MOCT, 2001). The solutions for reliable water resource management require better understanding of the catchment water cycle (i.e., accurate measurements of $E T$ and discharge, ET partitioning, and assessment of subsurface water storage) and its possible modification associated with natural and human disturbances (e.g., Bates et al., 2008). Although technical advances are being realized in various aspects of water management (Sustainable Water Resource Research Center, http://www.water21.re.kr/), the fundamental questions related to water cycles have been rarely explored for major catchments in the country.

The above characteristic hydrological conditions are expected to have a considerable effect on the carbon cycles in terrestrial ecosystems (e.g., Lee et al., 2007). As the country's greenhouse gas emission ranks in the world's top ten, the evaluation of carbon uptake capacity of terrestrial ecosystems has become indispensable information to cope with climate change protocols and to maintain a balance between sustainability and economic growths. Ecosystem carbon exchanges are being monitored using diverse, up-to-date methodologies (e.g., Kim et al., 2006). While each adopted technique has its own merits, the necessity of long-term, spatially averaged carbon exchange estimates is growing. For this purpose, the estimation of catchment scale transpiration, in conjunction with water use efficiency (WUE), can be used as a viable approach (e.g., Telmer and Veizer, 2000, 2001; Beer et al., 2007; Ferguson and Veizer, 2007).

Interpretation of the water and carbon exchange characteristics based on available data and information is an imminent task to establish proper plans and actions to mitigate the adverse effects associated with climate change. Therefore, in this paper, we discuss catchment scale water and carbon exchange characteristics in the Han River Basin, Korea on the basis of a long term, steady state water budget derived from relevant hydrological, meteorological and isotopic data. The Han River basin is particularly suitable because this highly populated area has been the center of various management practices related to water and carbon cycles (e.g., Choi et al., 2002). The objectives of this paper are to (1) derive and partition catchment scale $E T$ based on hydrological, meteorological, and stable isotope data, (2) examine the effects of precipitation on the annual variations in water and carbon cycles, and (3) examine the possibility of using the derived $T$ as a relative or absolute measure of $G P P$.

\section{Methods and materials}

\subsection{Theoretical backgrounds}

Assuming a steady-state water cycle and comparatively little change in the catchment water storage $(\Delta S \approx 0)$ at annual time scale, it is suggested that $E T$ can be derived from the difference between precipitation and discharge. In this practice, the water budget needs to be averaged for the mean residence time $(M R T)$ of water in the catchment, since the budget is expected to be closed with the time scale of $M R T$. Therefore,

$P-Q=E T$

$E T=E_{S}+E_{I}+T$

Measurements of $P$ and $Q$ are routinely conducted for many catchments in the world and therefore quality data are often available (e.g., Slack et al., 1992). Moreover, the regression between measured $P$ and $Q$ (with or without additional variables) often establishes catchment specific $P-Q$ relationship that can be applied to estimate discharge for ungauged catchments or for the period of missing observation (e.g., Boughton and Chiew, 2007).

The effect of evaporation (from soil and open water surface) during the residence of water in catchments is generally expressed as the enrichment of heavy isotopes in the remaining water due to kinetic fractionation effects. Exceptions are the total evaporation such as plant transpiration and intercepted evaporation that do not affect isotopic composition of remaining water and therefore can not be identified by isotopic methods. The effect of evaporation is graphically shown as the formation of local evaporation line (LEL) in $\delta^{18} \mathrm{O}-\delta \mathrm{D}$ cross plot that has a lower slope than Local Meteoric Water Line $(L M W L)$ (or Global Meteoric Water Line, GMWL) (Gonfiantini, 1986; Gat and Bowser, 1991). The lower slope of $L E L$ is due to the higher vapor pressure of ${ }^{1} \mathrm{H}^{2} \mathrm{HO}$ (mass of 19) than ${ }^{1} \mathrm{H}_{2}^{18} \mathrm{O}$ (mass of 20) and the resultant enrichment of ${ }^{18} \mathrm{O}$ compared to ${ }^{2} \mathrm{H}$ in the remaining water. Therefore, $E_{S}$ can be estimated by using an isotope mass balance relationship (Gonfiantini, 1986; Gat and Matsui, 1991; Gibson et al., 1993, 1996). Gonfiantini (1986) proposed an equation,

$$
\begin{aligned}
x & =E_{S} / P=\left(\delta_{S}-\delta_{I}\right)(1-h+\Delta \varepsilon) /\left[\left(\delta_{S}+1\right)(\Delta \varepsilon+\varepsilon / \alpha)\right. \\
& \left.+h \cdot\left(\delta a-\delta_{S}\right)\right]
\end{aligned}
$$

where $x$ is the percentage of $E_{S}$ with respect to the total water input into the area which mostly equals the total precipitation for independent catchments. $\delta_{S}$ is the weighted mean $\delta \mathrm{D}$ (or $\delta^{18} \mathrm{O}$ ) value measured at the mouth of the river. $\delta_{P}$ is the mean isotopic composition of precipitation in the basin. It is given by the intersection between the Meteoric Water Line (either global or local $M W L$ ) and the regression line for the measured $\delta \mathrm{D}$ and $\delta^{18} \mathrm{O}$ values of the river water (Gat and Matsui, 1991). $\delta_{a}$ is the mean $\delta \mathrm{D}$ (or $\delta^{18} \mathrm{O}$ ) 
value of the water vapor and is generally close to the equilibrium with local precipitation $\left(\delta_{a}=\delta_{I}-\varepsilon^{*}\right) . h$ is the mean relative humidity, $\alpha$ the equilibrium fractionation factor for oxygen ( $\left.\ln \alpha=1137 T^{-2}-0.4156 T^{-1}-0.00207\right)$ and hydrogen isotopes $\left(\ln \alpha=24844 T^{-2}-76.248 T^{-1}+0.05261\right)$ (Friedman and O'Neil, 1977), $T$ is temperature in $\mathrm{K}, \Delta \varepsilon$ is the kinetic enrichment factor for oxygen $(14.2(1-h))$ and hydrogen isotopes $(12.5(1-h))$, and $\varepsilon^{*}=1000(\alpha-1)$. The relation has been applied for the estimation of evaporation rates from lakes (e.g., Gonfiantini, 1986; Gibson and Edwards, 2002) and for evaporation studies on various forest ecosystems (e.g., Wang and Yakir, 2000; Yepez et al., 2003; Tsujimura et al., 2007). Catchment is a mixed system with evaporation from both open water bodies and ecosystem and catchment scale evaporation has been estimated by Gat and Matsui (1991), Gibson et al. (1993), and Telmer and Veizer (2000).

$E_{I}$ is one of the most difficult components to estimate in the water budget at regional scale. A number of field and modeling studies have been conducted to understand the extent and mechanisms of interception for diverse vegetation types and precipitation regimes (e.g., Gash, 1979). $E_{I}$ at catchment scales and its inter-annual variations are, however, poorly known (e.g., Cuartas et al., 2007). The amount of $E_{I}$ is mainly related to the intensity and duration of precipitation, meteorological conditions (e.g., air temperature, wind speed), and the type and structure of vegetation (e.g., Gash et al., 1995). Regarding inter-annual variations, the ratio of $E_{I}$ to $P$ is known to decrease with increasing amount of annual precipitation (e.g., Cuartas et al., 2007). The magnitude and pattern of precipitation likely play a critical role in controlling annual $E_{I}$, since the inter-annual variations in meteorological and vegetation-related parameters are relatively small compared to those in precipitation whose magnitude may vary up to over $100 \%$. de Groen and Savenije (2006) suggested an equation to estimate regionally representative monthly $E_{I}$,

$E_{I}=P_{m} \cdot(1-\exp (-D / \beta))$

where $P_{m}$ is the monthly precipitation (mm), $D$ is the daily interception threshold $\left(\mathrm{mm} \mathrm{d}^{-1}\right)$ indicating the amount of water which can be stored at the vegetation surface, and $\beta$ is the expected amount of rainfall on a rainy day $\left(\mathrm{mm} \mathrm{d}^{-1}\right)$. The equation can be used to calculate $E_{I}$ during multiple rain events primarily based on the total monthly rainfall during the study period.

In this study, the two important variables $(D$ and $\beta$ ) in Eq. 4 and monthly precipitation $\left(P_{m}\right)$ were estimated from relevant studies and long-term meteorological data. $D$ is related to canopy structure and therefore can be species and biome specific. Kim et al. (2005) conducted field measurement of interception for selective vegetation types in Korea. They reported year long data of precipitation, throughfall and stemflow. The data were analyzed using precipitation (Xaxis) against throughfall and stemflow cross plots. For each plot, a best-fit line was determined by regression and its $\mathrm{x}$ intercept was interpreted as the threshold of precipitation below which no throughfall or stemflow was generated (Bryant et al., 2005). The amount of precipitation thus determined was considered as the daily interception threshold expressed as mm per day.

$\beta$ can be determined by two step procedure. First, $\beta$ was calculated from long-term meteorological data (mean for the period from 1971 to 2000 from Korea Meteorological Administration) by dividing mean monthly precipitation from representative meteorological stations in the Han River Basin by the number of rainy days (with more than $0.1 \mathrm{~mm}$ of rainfall) of each month. Second, as pointed out by de Groen and Savenije (2006), since $\beta$ has a strong correlation with $P_{m}$, we derived the catchment specific relationship between $P_{m}$ and $\beta$ for the study area. Then, using this relationship, the catchment scale $\beta$ was calculated from the area-averaged monthly precipitation data for the period from 1966 to 2007.

$T$ can be finally derived from the residual of $E T$ after accounting for $E_{S}$ and $E_{I} . T$ constitutes the denominator term of WUE that is expressed as the ratio of the amount of carbon to water simultaneously exchanged through stomata during photosynthesis. WUE is a quantitative indicator of the interdependency between water and carbon cycles and therefore, if $T$ is estimated by independent methods, can be used to constrain the amount of carbon uptake at various spatial and temporal scales (e.g., Lee and Veizer, 2003). Especially, if the WUE is defined as the ratio of carbon to water exchanges at leaf level averaged for the comparable period of $T$ estimates, gross primary productivity $(G P P)$ can be estimated as:

$$
G P P(\mathrm{~g} \mathrm{C})=T\left(\mathrm{~kg} \mathrm{H}_{2} \mathrm{O}\right) \cdot W U E\left(\mathrm{~g} \mathrm{C} \mathrm{kg} \mathrm{H}_{2} \mathrm{O}^{-1}\right) .
$$

\subsection{The study area}

The Han River Basin is located in the center of the Korean Peninsula occupied by more than 20 million residents with various industrial and agricultural activities. The Han River originates from the eastern mountain range, flows westward, and discharges into the Yellow Sea (Fig. 1a). The river and its tributaries serve as the source of fresh water in and around the capital region of the country. The basin, with an area of $26100 \mathrm{~km}^{2}$, consists mainly of temperate mixed forests, croplands including rice paddies, and urban areas. Mean annual temperature of the basin is $\sim 11^{\circ} \mathrm{C}$ and the mean annual precipitation from 1966 to 2007 amounts to 1244 mm (WAMIS, www.wamis.go.kr). The study sites consist of nested catchments with successive drainage orders in the Han River basin (Fig. 1b). The area of studied drainages ranges from $\sim 2$ to $\sim 10^{4} \mathrm{~km}^{2}$. We arbitrarily separated the studied drainages into the small and large catchments. The small catchments include Gwangneung $\left(\sim 2 \mathrm{~km}^{2}\right)$, Bongsunsa $\left(\sim 40 \mathrm{~km}^{2}\right)$ and Toegyewon $\left(201 \mathrm{~km}^{2}\right)$. The large catchments indicate the entire Han River basin and its two 

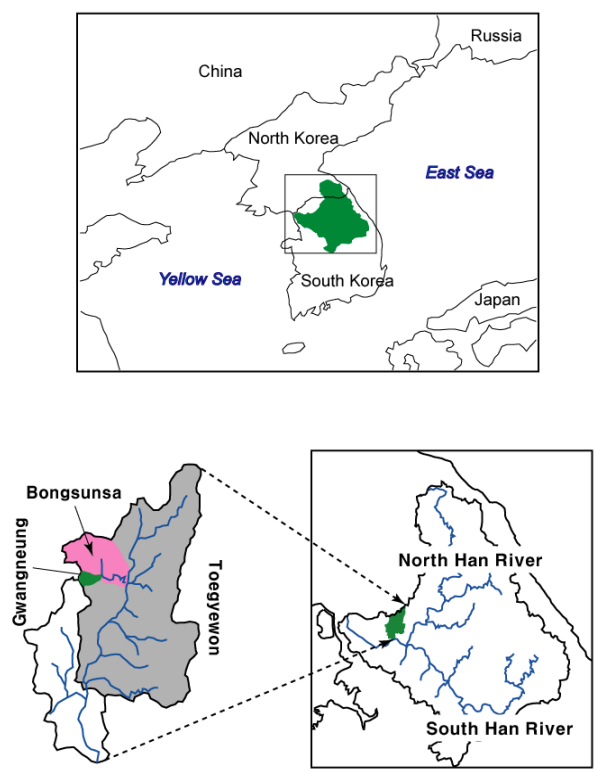

(A)

Han River Basin

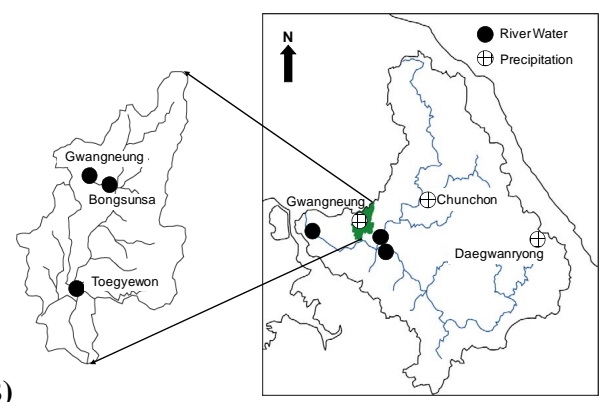

(B)

Fig. 1. Maps showing (A) the Han River Basin and its tributaries (adopted from Kim et al., 2006), (B) sampling locations.

major tributaries, the North Han $\left(10744 \mathrm{~km}^{2}\right)$ and the South Han $\left(12407 \mathrm{~km}^{2}\right)$. Among them, the Gwangneung catchment is an independent first order drainage basin where comprehensive ecohydrological studies have been conducted such as tower flux, meteorological, ecological, biogeochemical, isotopic and satellite-based measurements, and modeling (e.g., Kim et al., 2006; Kang et al., 2009; Kwon et al., 2010).

\subsection{Measurements and analysis}

For this study, samples of river water were collected at the outlet of the Han River and its tributaries once for large catchments and twice for small catchments for each month from December 2004 to June 2006. Monthly composite samples of precipitation were collected during the same period at three different locations (i.e., Gwangneung, Daegwanryong and Chunchon) in the basin to examine possible spatial variability in isotope composition (Fig. 1b). The sampling locations represent varying precipitation regimes with mean annual rainfalls of $1267 \mathrm{~mm}$ (Chunchon), $1434 \mathrm{~mm}$ (Gwangne- ung) and $1717 \mathrm{~mm}$ (Daegwanryong) (www.kma.go.kr). For the rain sampling, a $20 \mathrm{~L}$ flask with a funnel $(0.25$ or $0.45 \mathrm{~m}$ in diameter depending on the expected monthly rainfall) was used. The flask was kept in a stainless steel cabinet to protect the samples in the field condition and to avoid direct sunlight. The funnel was inserted through a hole at the top of the cabinet and the rain water collected by the funnel was drained to the flask by a hose. Paraffin oil with the specific gravity of 0.86 was used to prevent evaporation during the sampling period. During the winter, a heated $\left(\sim 10^{\circ} \mathrm{C}\right)$ stainless steel funnel was used to collect snow samples. However, some of the samples collected during the winter season (November February) indicated an evaporative enrichment in the isotopic composition. We estimated the possible evaporation effect by calculating $d$-excess and samples with negative $d$-excess values were excluded in further analyses. After excluding these samples, the sampled precipitation corresponds to $97 \%$ (Gwangneung), 92\% (Chunchon) and 94\% (Daegwanryong) of the annual precipitation and can be considered as representative of the study period.

All isotope analyses were conducted at the Stable Isotope Laboratory of the Korea Basic Science Institute (KBSI). For the determination of ${ }^{18} \mathrm{O} /{ }^{16} \mathrm{O}$ ratios, small amount of $\mathrm{CO}_{2}$ gas was equilibrated with $0.2 \mathrm{ml}$ of water at $25 \pm 0.1^{\circ} \mathrm{C}$ (Epstein and Mayeda, 1953). Then, $\mathrm{CO}_{2}$ was extracted and purified cryogenically. For D/H ratios, small amount of water sample was reacted with metallic chromium to release $\mathrm{H}_{2}$ gas using an automatic on-line sample preparation system (Pyr-OH Model, GV Instruments, Limited) (Morrison et al., 2001). Both oxygen and hydrogen isotope ratios were analyzed using a stable isotope ratio mass spectrometer (Isoprime model, GV Instruments, Limited). All isotope data are reported as $\delta$ values relative to V-SMOW. The analytical reproducibility of oxygen and hydrogen isotope analysis was $\pm 0.1 \%$ and $\pm 1 \%$, respectively.

\subsection{Auxiliary database}

In addition to the above on-site measurements, other relevant meteorological, hydrological and isotope data for the study area were obtained from various sources. The WAMIS database (www.wamis.go.kr) maintained by the Han River Flood Control Office provides river discharges, watershed averaged daily precipitation from 1966 onward and other hydrological, meteorological, statistical data for the major watersheds in Korea. River discharge data for the Han River are also available through RivDIS database (http://daac.ornl.gov/ RIVDIS/rivdis.html). Hydrological and meteorological information for the Gwangneung catchment can be found from HydroKorea database (http://hydrokorea.org). Meteorological data for the study area are available from the Korea Meteorological Administration (www.kma.go.kr). Hydrogen and oxygen isotope data of the Han River and precipitation for the period of 1991 1995 and 1995 1997 were reported by 


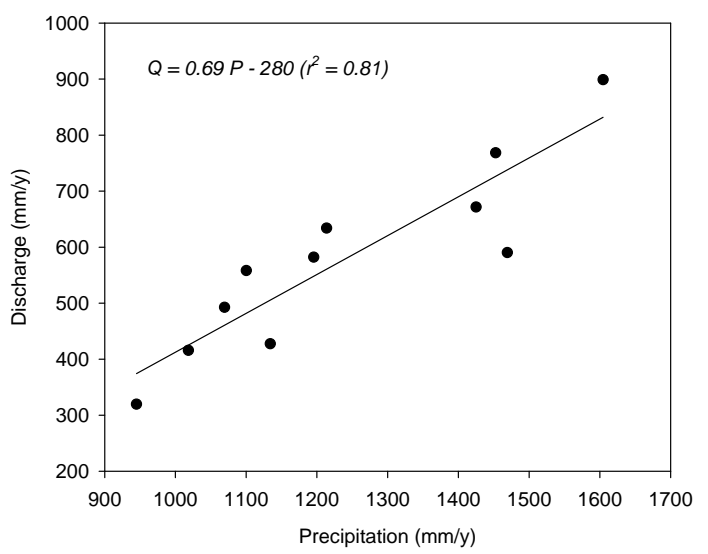

Fig. 2. Long-term precipitation and discharge relationship in the Han River.

Lee and Lee (1999). Yu et al. (2007) reported isotope composition of precipitation in Chunchon from 2002 to 2004.

\section{Results}

\subsection{Estimation of ET based on long-term precipitation and discharge data}

From RivDIS (v.1.1) database, the mean annual discharge from the Han River basin was calculated as $16.0 \mathrm{~km}^{3}$ for the period from 1955 to 1979 (Data from 1973 to 1975 are missing). The natural discharge of the Han River has not been routinely monitored since then, while discharges from the dams in the middle and upstream areas of the river channel are being regularly monitored for the purpose of flood and drought controls. Therefore, the RivDIS database is the only source of natural discharge information of the river that is minimally disturbed by artificial structures and manipulation.

The long-term correlation between annual $P$ and $Q$ is expressed as " $Q=0.69 \cdot P-280\left(r^{2}=0.81\right)$ " (Fig. 2). We applied this relation to estimate annual $Q$ of the river for the ungauged period. From 1966 to 2007, the mean annual $P$ and $Q$ were estimated as $1244 \mathrm{~mm}$ and $579 \mathrm{~mm}$ respectively, and $666 \mathrm{~mm}$ was thus apportioned to the catchment scale mean ET (Table 1). For the annual change of $P$ ranging from 909 to $1911 \mathrm{~mm} \mathrm{y}^{-1}$, the estimated $Q$ varied from 347 to $1039 \mathrm{~mm} \mathrm{y}^{-1}$. The variability of estimated $E T$ was smaller than that of $Q$ ranging from 562 to $873 \mathrm{~mm} \mathrm{y}^{-1}$. As $P$ increased, both $Q$ and $E T$ became greater but the latter was somewhat conservative. The proportion of $Q$ relative to $P$ increased as $P$ increased while that of $E T$ decreased.

The derived relation was validated using the data from other studies. In the Gwangneung catchment, the estimated $Q$ in 2005 and 2006 was $52 \%$ of annual $P$ based on the relation and is similar to the field measurement, i.e., $57 \%$ (HydroKorea database). Likewise, the nationwide ET mapping in 2006 based on the weather research and forecasting model indicated that $50 \%$ of annual $P$ was allocated to $E T$ for the entire Han River basin (HydroKorea database), which also resulted in the other $50 \%$ of $P$ to be $Q$ (Table 1).

Uncertainties may arise due to the changes in climatic conditions and land cover characteristics in the catchment. In the study area, data are not available to examine possible temporal variability of $P-Q$ relation. To examine the effect of temporal changes in catchment characteristics, we used a long-term $P$ and $Q$ data for the Ohio River in USA (http://waterdata.usgs.gov/nwis/sw). The $P-Q$ relationship was derived for every decade from 1929 to 1999 and it turned out that the correlations (in terms of slope and y-intercept) changed with time. We estimated $Q$ from $P$ using various $P-Q$ correlations determined for each decade and compared the results. The calculated $Q$ using various $P-Q$ relations varied with less than $\pm 10 \%$ SD in the range of $P$ from 1000 to $2000 \mathrm{~mm}$. The uncertainties tend to increase as $P$ becomes less than $1000 \mathrm{~mm}$ and greater than $2000 \mathrm{~mm}$. Although these results may not be directly applicable to our study area, we consider $\pm 10 \%$ SD as the possible extent of uncertainty in the estimated $Q$ related to the changes in climatic and landcover characteristics.

In this practice, we assumed that the water budget closes at annual time scale in the study area. This assumption is valid for the Han River basin since the MRT of water in the basin was estimated to be $\sim 1$ year or less (Kim et al., 2009). The steady state assumption (i.e., annual variability of water storage is insignificant $(\Delta S \approx 0)$ ) is difficult to verify (Milly et al., 2008; Taylor, 2009). However, the average water level of the major reservoirs in the Han River showed minimal annual variability $( \pm 3 \%)$, indicating that the water storage in the basin does not change significantly at annual time scale (WAMIS). In this context, we can assert that the difference between $P$ and $Q$ corresponds to the catchment scale annual $E T$ or at least to the amount of water potentially allocated for ET.

\subsection{Estimation of $E_{S}$ from stable isotope data}

\subsubsection{River waters}

In the studied catchments, the isotope composition of river waters exhibited limited variability with time and water regimes (Fig. 3a, b). For the small catchments with an increasing order in size, the annual averages (weighted by discharge) $\delta^{18} \mathrm{O}$ and $\delta \mathrm{D}$ of river waters were respectively $-8.9 \pm 0.3 \%$ and $-64 \pm 3 \%$ o for Gwangneung, $-8.8 \pm 0.4 \%$ and $-63 \pm 3 \%$ for Bongsunsa, and $-8.7 \pm 0.5 \%$ and $-63 \pm 4 \%$ o for Toegyewon (Table 2). Isotope composition of river waters was lowest during July $\sim$ September (i.e., summer monsoon and typhoon seasons) due to the input of rainfalls with low $\delta^{18} \mathrm{O}$ and $\delta \mathrm{D}$. The isotope composition gradually increased afterward and reached the highest values in May $\sim$ June. For 
Table 1. Precipitation and estimated water budget components in the Han River basin from 1966 to 2007 ( $P$ : precipitation, $Q$ : discharge, $E T$ : evapotranspiration, $E_{I}$ : evaporation from intercepted rainfall, $T$ : transpiration). Evaporation from soil/water surfaces $\left(E_{S}\right)$ was not shown in the table, although its amount was included in the water budget calculation. $P$ is from WAMIS database (www.wamis.go.kr) and the rest of water budget was derived by a series of exercise discussed in the text.

\begin{tabular}{|c|c|c|c|c|c|c|c|c|c|}
\hline Year & $P^{*}$ & $Q^{*}$ & $Q(\%)$ & $E T^{*}$ & $E T(\%)$ & $E_{I}^{*}$ & $E_{I}(\%)$ & $T^{*}$ & $T(\%)$ \\
\hline 1966 & 1605 & 827 & 52 & 777 & 48 & 391 & 24 & 369 & 23 \\
\hline 1967 & 1069 & 458 & 43 & 612 & 57 & 323 & 30 & 276 & 26 \\
\hline 1968 & 1134 & 503 & 44 & 632 & 56 & 323 & 29 & 296 & 26 \\
\hline 1969 & 1453 & 722 & 50 & 730 & 50 & 359 & 25 & 355 & 25 \\
\hline 1970 & 1425 & 703 & 49 & 722 & 51 & 351 & 25 & 355 & 25 \\
\hline 1971 & 1100 & 479 & 44 & 621 & 56 & 314 & 29 & 295 & 27 \\
\hline 1972 & 1469 & 734 & 50 & 735 & 50 & 387 & 26 & 332 & 23 \\
\hline 1973 & 932 & 363 & 39 & 569 & 61 & 299 & 32 & 260 & 28 \\
\hline 1974 & 1096 & 477 & 44 & 620 & 57 & 319 & 29 & 289 & 26 \\
\hline 1975 & 1155 & 517 & 45 & 638 & 55 & 327 & 28 & 299 & 26 \\
\hline 1976 & 1018 & 423 & 42 & 596 & 59 & 305 & 30 & 280 & 27 \\
\hline 1977 & 945 & 372 & 39 & 573 & 61 & 288 & 31 & 275 & 29 \\
\hline 1978 & 1195 & 545 & 46 & 651 & 54 & 325 & 27 & 312 & 26 \\
\hline 1979 & 1214 & 557 & 46 & 656 & 54 & 338 & 28 & 305 & 25 \\
\hline 1980 & 1208 & 554 & 46 & 655 & 54 & 328 & 27 & 313 & 26 \\
\hline 1981 & 1317 & 629 & 48 & 688 & 52 & 346 & 26 & 328 & 25 \\
\hline 1982 & 912 & 349 & 38 & 563 & 62 & 281 & 31 & 271 & 30 \\
\hline 1983 & 993 & 405 & 41 & 588 & 59 & 303 & 31 & 274 & 28 \\
\hline 1984 & 1297 & 615 & 47 & 682 & 53 & 339 & 26 & 329 & 25 \\
\hline 1985 & 1266 & 594 & 47 & 673 & 53 & 354 & 28 & 305 & 24 \\
\hline 1986 & 1078 & 464 & 43 & 614 & 57 & 322 & 30 & 280 & 26 \\
\hline 1987 & 1503 & 757 & 50 & 746 & 50 & 376 & 25 & 353 & 24 \\
\hline 1988 & 909 & 347 & 38 & 562 & 62 & 273 & 30 & 279 & 31 \\
\hline 1989 & 1293 & 612 & 47 & 681 & 53 & 355 & 27 & 312 & 24 \\
\hline 1990 & 1911 & 1039 & 54 & 873 & 46 & 435 & 23 & 417 & 22 \\
\hline 1991 & 1201 & 549 & 46 & 652 & 54 & 340 & 28 & 299 & 25 \\
\hline 1992 & 1111 & 487 & 44 & 624 & 56 & 337 & 30 & 275 & 25 \\
\hline 1993 & 1212 & 556 & 46 & 656 & 54 & 344 & 28 & 299 & 25 \\
\hline 1994 & 1025 & 427 & 42 & 598 & 58 & 309 & 30 & 278 & 27 \\
\hline 1995 & 1374 & 668 & 49 & 706 & 51 & 352 & 26 & 339 & 25 \\
\hline 1996 & 994 & 406 & 41 & 588 & 59 & 308 & 31 & 269 & 27 \\
\hline 1997 & 1255 & 586 & 47 & 669 & 53 & 352 & 28 & 303 & 24 \\
\hline 1998 & 1597 & 822 & 52 & 775 & 49 & 391 & 25 & 367 & 23 \\
\hline 1999 & 1500 & 755 & 50 & 745 & 50 & 357 & 24 & 371 & 25 \\
\hline 2000 & 1138 & 505 & 44 & 633 & 56 & 316 & 28 & 305 & 27 \\
\hline 2001 & 961 & 383 & 40 & 578 & 60 & 293 & 31 & 275 & 29 \\
\hline 2002 & 1257 & 587 & 47 & 670 & 53 & 334 & 27 & 322 & 26 \\
\hline 2003 & 1686 & 883 & 53 & 803 & 48 & 397 & 24 & 387 & 23 \\
\hline 2004 & 1367 & 663 & 49 & 704 & 52 & 350 & 26 & 338 & 25 \\
\hline 2005 & 1325 & 634 & 48 & 691 & 52 & 335 & 25 & 342 & 26 \\
\hline 2006 & 1407 & 691 & 49 & 716 & 51 & 361 & 26 & 340 & 24 \\
\hline 2007 & 1348 & 650 & 48 & 698 & 52 & 336 & 25 & 347 & 26 \\
\hline Average & 1244 & 579 & 46 & 666 & 54 & 337 & 28 & 315 & 26 \\
\hline
\end{tabular}

* Units are in $\mathrm{mm} \mathrm{y}^{-1}$.

the large catchments, annual averages (weighted by discharge) of $\delta^{18} \mathrm{O}$ and $\delta \mathrm{D}$ of river waters were respectively $-9.1 \pm 0.4 \%$ and $-66 \pm 3 \%$ for the South Han, $-9.4 \pm 0.2 \%$ and $-68 \pm 1 \%$ for the North Han, and $-9.2 \pm 0.3 \%$ and $-66 \pm 2 \%$ for the Han River. The sea- sonal variations in $\delta^{18} \mathrm{O}$ and $\delta \mathrm{D}$ of river waters indicated consistently low values in summer (July $\sim$ August) and in winter (December $\sim$ January or February $\sim$ March, depending on years). 
Table 2. Discharge weighted mean isotope compositions of the rivers, and the slopes and intercepts of Local Evaporation Line (LEL) for the period from 2005 to 2006 .

\begin{tabular}{lccccc}
\hline \multirow{2}{*}{ Catchments } & \multicolumn{2}{c}{ Weighted average river water* } & \multicolumn{3}{c}{ Local Evaporation Line $(L E L)$} \\
& $\delta^{18} \mathrm{O}$ & $\delta \mathrm{D}$ & Slope & Y-intercept & $r^{2}$ \\
\hline Gwangneung & $-8.9 \pm 0.3$ & $-64 \pm 3$ & 7.23 & 1.73 & 0.70 \\
Bongsunsa & $-8.8 \pm 0.4$ & $-63 \pm 3$ & 6.19 & -8.18 & 0.63 \\
Toegyewon & $-8.7 \pm 0.5$ & $-63 \pm 4$ & 6.16 & -8.91 & 0.82 \\
South Han & $-9.1 \pm 0.4$ & $-66 \pm 3$ & 8.56 & 11.64 & 0.88 \\
North Han & $-9.4 \pm 0.2$ & $-68 \pm 1$ & 5.02 & -20.09 & 0.66 \\
Han River & $-9.2 \pm 0.3$ & $-66 \pm 2$ & 4.79 & -22.01 & 0.72 \\
\hline
\end{tabular}

${ }^{*}$ Units are in $\%$ o.

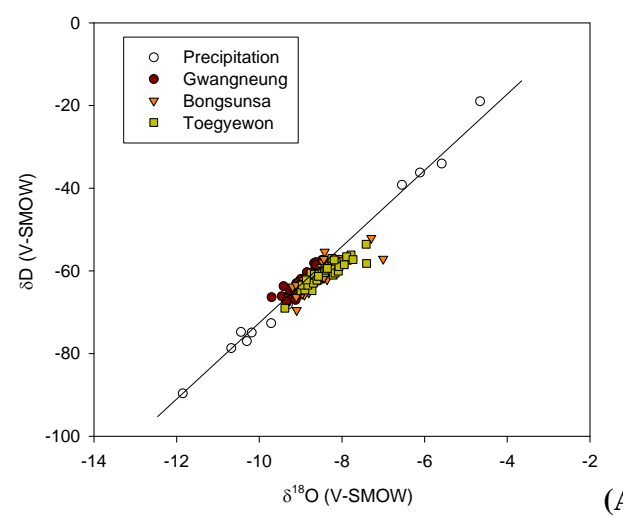

(A)

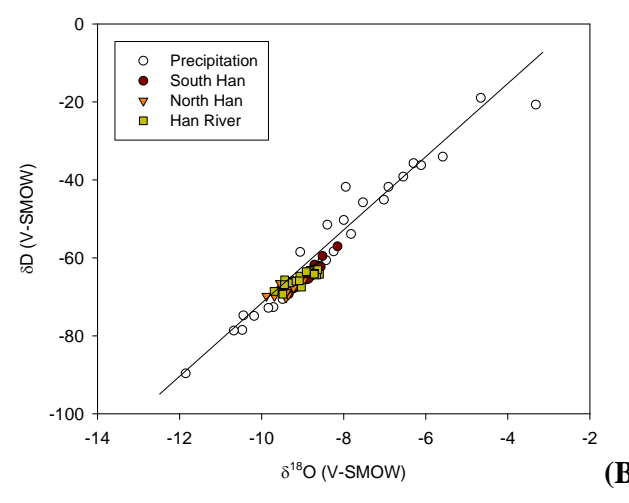

Fig. 3. Isotope composition of river waters (A) for small and (B) large catchments. Isotope composition of precipitation is from Gwangneung for the small catchments and from all three locations for the large catchments.

In $\delta^{18} \mathrm{O}-\delta \mathrm{D}$ cross plot, the isotope composition of river waters tends to form $L E L$ of which the slope is lower than that of $L M W L$ if evaporation affected the isotope composition of water during its residence in the catchment. However, the $L E L$ is often undefined or has similar slope and intercept with those of $L M W L$ when the effect of evaporation is negligible (e.g., Coplen and Kendall, 2000). In the studied catchments, the LELs were not obvious since the isotope compositions of river waters were mostly clustered around the presumed average isotope composition of precipitation (Fig. 3a, b). Ta- ble 2 shows the slopes and intercepts of $L E L$ in each catchment. As a reference, the GMWL established by the global precipitation has a regression expressed as $\delta \mathrm{D}=8.17( \pm 0.06)$ $\cdot \delta^{18} \mathrm{O}+10.35( \pm 0.65)$ (Rozanski et al., 1993).

\subsubsection{Precipitation}

The isotope composition of precipitation from three sampling locations together form a $L M W L$ that is expressed as $\delta \mathrm{D}=8.9 \delta^{18} \mathrm{O}+17 \quad\left(r^{2}=0.93\right)$. The slope and $d$ excess $\left(\delta \mathrm{D}-8 \times \delta^{18} \mathrm{O}\right)$ are greater than those of $G M W L$. The $L M W L$ from each sampling location is expressed as $\delta \mathrm{D}=10.0 \delta^{18} \mathrm{O}+27.7$ for Daegwanryong, $\delta \mathrm{D}=10.2 \delta^{18} \mathrm{O}+28.4$ for Gwangneung, and $\delta \mathrm{D}=8.1 \delta^{18} \mathrm{O}+10.7$ for Chunchon. The $L M W L$ in Chunchon is similar to GMWL and is clearly different from that of Gwangneung and Daegwanryong. The unique characteristic of precipitation in Chunchon is also confirmed from the data of $\mathrm{Yu}$ et al. (2007) for the period from 2002 to 2004. A more detailed discussion about the isotope composition of precipitation in Korea and the study area can be found in Lee and Lee (1999).

The average isotope composition of the precipitation during the study period was estimated using two different ways. First, following Gat and Matsui (1991), the intersection between $L M W L$ and $L E L$ was determined as the average isotope composition of the precipitation. The method is based on a systematic relationship between the isotope composition of precipitation as the source and river water as its derivative. Another way of estimating average isotope composition of precipitation is simply obtaining weighted averages during the study period. Table 3 shows the average isotope composition of precipitation determined by both methods that provided consistent results within analytical uncertainties except those of North Han and South Han River basin. For the South Han River basin, the average isotope composition of precipitation determined by the intersection method was much lower than the weighted averages. The discrepancy is due to the fact that the $L E L$ and $L M W L$ of the South Han River basin had similar slopes, thereby increasing the uncertainty of the coordinates of the intersection. For the North Han River basin, the weighted average isotope composition 
Table 3. The mean isotope composition of precipitation in the studied catchments derived from two different methods for the period from 2005 to 2006 .

\begin{tabular}{lcclc}
\hline \multirow{3}{*}{ Catchments } & \multicolumn{3}{c}{$L M W L-L E L$} & \multicolumn{2}{c}{ Intersection method } & \multicolumn{2}{c}{ Weighted averages } \\
& $\delta^{18} \mathrm{O}$ & $\delta \mathrm{D}$ & $\delta^{18} \mathrm{O}$ & $\delta \mathrm{D}$ \\
\hline Gwangneung & -9.0 & -64 & -9.1 & -65 \\
Bongsunsa & -9.2 & -65 & -9.1 & -65 \\
Toegyewon & -9.3 & -66 & -9.1 & -65 \\
South Han & -11.2 & -84 & -9.7 & -70 \\
North Han & -9.8 & -69 & -9.1 & -65 \\
Han River & -9.5 & -67 & -9.3 & -67 \\
\hline
\end{tabular}

Units are in $\%$.

of precipitation was greater than that of river water, which is unreasonable considering the source-product relationship. In the North Han River basin, a greater lag time can be assumed between the precipitation and the river water generation. Therefore, the weighted average during the study period may not indicate the direct source of the river water during the study period. In this hydrological setting, the river water was assumed to have been generated from the precipitation occurred prior to the sampling period of this study. The isotope data of precipitation in Chunchon from 2002 to 2004 indicated similar weighted average composition to those obtained by the $L M W L-L E L$ intersection (Yu et al., 2007).

\subsubsection{Estimation of $E_{S}$}

Using the mean isotope compositions of source precipitation and river waters, the amount of evaporation was calculated based on the isotope mass balance relation (Eq. 3). $E_{S}$ was estimated to account for $0.3 \sim 2.3 \%$ of annual precipitation in the studied catchments without a significant correlation with the catchment scale. For the entire Han River basin, $E_{S}$ was estimated as $1.1 \pm 2 \%$ of the annual $P$. Considering the uncertainties with the estimation of the mean isotope composition of $P$ and $Q$, the calculated proportion of $E_{S}$ is within the uncertainty of the adopted isotope technique. Nevertheless, it is clear that $E_{S}$ is relatively small compared to other water cycle components such as $Q, E T$, and $E_{I}$. Similar results were reported from many watersheds in the world where the evaporation component was minor or largely unidentified on the basis of isotope technique (e.g., Coplen and Kendall, 2000; Lee and Veizer, 2003). A previous isotope study for the Han River basin indicated $\sim 2.5 \%$ of $E_{S}$ relative to annual $P$ during 1993 1996 (Lee and Lee, 1999). The contribution of $E_{S}$ to $E T$ in the Han River basin can be considered minor based on two independent isotope studies conducted $\sim 10$ years apart. It is, however, necessary to monitor isotope composition of river waters for possible annual variations in $E_{S}$ and more accurate assessment of the water budget. The $E T$ in the Han River Basin mainly consisted of $T$ and $E_{I}$

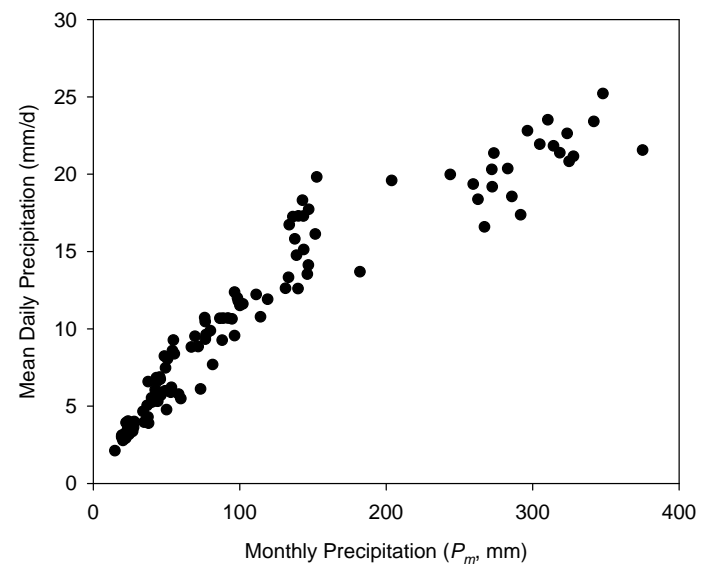

Fig. 4. The relationship between the expected amount of precipitation on a rainy day $\left(\beta\right.$ in $\left.\mathrm{mm} \mathrm{d}^{-1}\right)$ and monthly total precipitation for representative meteorological stations in the Han River basin. Data are the mean for the period from 1971 to 2000.

that are directly and indirectly controlled by plant productivity, emphasizing the importance of biological control in modeling and predicting water cycle in the study area.

It should be noted that approximately $\sim 5$ billion tons ( $\sim 15 \%$ of the annual $P$ ) of fresh water is being used (but in large part eventually returns to the river system) annually for various purposes in the study area (WAMIS). The household usage is the largest and the irrigation is the second largest. Among these water use practices, total evaporation (such as crop transpiration) will not affect the isotope composition of the remaining water as previously discussed in Sect. 2.1. Although the catchment averaged isotopic composition does not indicate sizable evaporation related to water utilization, water cycles in urban and agricultural areas and their effect on isotopic composition deserve further consideration especially for the issues related to the water resource management.

\subsection{Estimation of $E_{I}$}

Based on the data in Kim et al. (2005), we determined the values of seasonally averaged $D$ for various forest types, which ranged from 2.1 to $4.2 \mathrm{~mm} \mathrm{~d}^{-1}$. In this study, we used the value of 4.2 from mixed forests as a representative $D$. The calculated $\beta$ based on the 30-year mean monthly precipitation data from KMA ranged from 2.1 to $25 \mathrm{~mm} \mathrm{~d}^{-1}$, which increased with increasing monthly precipitation amount (Fig. 4). A strong dependence of $\beta$ on $P_{m}$ is obvious from the result of a linear regression of $\beta=a\left(1-\mathrm{e}^{-b P m}\right)$, where $a=24.83, b=0.0063\left(r^{2}=0.96\right)$. Hence, we used this relationship to calculate the catchment scale $\beta$ from 1966 to 2007 .

The estimated $E_{I}$ ranged from 273 to $435 \mathrm{mmy}^{-1}$ (or $23 \sim 32 \%$ of annual $P$ ) in the Han River basin from 1966 to 2007 (Table 1). While there was an overall positive 
correlation between $E_{I}$ and $P, E_{I} / P$ decreased as $P$ increased. As expected from Eq. $4, E_{I} / P_{m}$ was higher during the dry months when $\beta$ was generally similar to or smaller than $D$, whereas the ratio dropped during the wet months when $\beta$ was high. The use of seasonally averaged $D$ is likely to overestimate $E_{I}$ during dry months (non-growing season for deciduous species with low leaf area) and underestimate during wet months (growing season with high leaf area). To improve the accuracy of $E_{I}$ estimate based on this statistical approach, the seasonal change in $D$ needs to be investigated for various biome types.

\subsection{Estimation of catchment scale transpiration}

Based on the previous results, $T$ was estimated as the residual of $E T$ after accounting for $E_{S}$ and $E_{I}$ (Table 1). For the Han River basin, $T$ varied from 260 to $417 \mathrm{~mm} \mathrm{y}^{-1}$ or from 22 to $31 \%$ of the annual $P$. The ratio of $T$ to $P$ increased with decreasing $P$. Ferguson and Veizer (2007) estimated the amount of $T$ to be $\sim 55 \%$ of annual precipitation for water-limited catchments (i.e., the annual $P$ is less than $\sim 1500 \mathrm{~mm}$ ) in the world. Our estimate is lower than their global average, suggesting that the relationship between $P$ and $T$ can be catchment-specific with different hydrogeological, meteorological, and land cover characteristics. The evaluation of the consistency of our results against those from other studies is yet to come due the paucity of comprehensive field and model-derived data.

\section{Discussion}

\subsection{Annual variation of catchment water budget}

In this study, the catchment water budget was derived largely based on empirical and theoretical relationships. These relationships consider the amount and pattern of precipitation as the main variables. As clearly shown in the $P-Q$ relation derived in this study, the dominant effect of precipitation is expected in successive partitioning of water budget components. For example, the amount of $P$ is responsible for over $\sim 80 \%$ of the annual variability in $Q$ (and $E T$ as well). Overall, the increase in $P$ increases the amount of $Q, E T, E_{I}$ and $T$. However, the proportion relative to $P$ increases only for $Q$ while it decreases for $E T, E_{I}$ and $T$. The effect of changing precipitation regime on $E_{S}$ is not clear with the currently available data. For a more reliable water budget assessment, factors other than $P$ need to be considered in the estimation of $Q$ and $E_{I}$. Based on our estimates, for the annual variability in precipitation of $\sim 110 \%, T$ varies by $\sim 62 \%$. Can we then expect the same extent of variability in the ecosystem productivity? Answers for this question are discussed in the next section.

\subsection{Implications for catchment scale carbon uptake}

The estimated $T$ indicates the amount of water transpired from leaves in exchange of carbon dioxide during photosynthesis and therefore, can be used as an indicator of the catchment scale carbon uptake, i.e., Gross or Net Primary Productivity. This requires an independent estimation of $W U E$ at the corresponding spatial scales. The possibility of using $T$ and $W U E$ to estimate catchment scale productivity has been examined in previous studies without an in-depth consideration of spatially representative WUE (Telmer and Veizer, 2000; Lee and Veizer, 2003). Recently, Beer et al. (2007) reported continental scale GPP estimates based on $E T$ derived from hydrological data assuming a simple water balance relation and WUE $(=G P P / E T)$ up-scaled from tower flux measurements. The study of Beer et al. (2007) provided an independent method to derive regional scale $W U E$ based on field measurements and modelling. Such an approach is novel and practical, yet the use of $E T$ as the quotient of WUE may incorporate uncertainties since $E_{S}$ may constitute a considerable portion of $E T$ depending on the types of ecosystems (e.g., Gat and Matsui, 1991; Williams et al., 2004) and another non-productive water exchange, $E_{I}$, is inevitably incorporated.

Only sporadic information is available on the carbon exchanges in our study area that can be combined with the water budget estimates derived from this study. The leaf level WUE has been determined in the Gwangneung catchment for Quercus and Carpinus sp. based on leaf carbon isotope composition from 2003 to 2005 (Chae et al., 2009). The growing season averaged WUE of Quercus sp. ranged from $8.9 \pm 1.8$ to $10.3 \pm 4.4 \mathrm{~g} \mathrm{C}\left(\mathrm{kg} \mathrm{H}_{2} \mathrm{O}\right)^{-1}$ and that of Carpinus

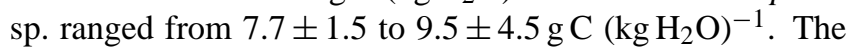
derived WUE cannot be used directly to estimate catchment scale annual GPP since WUE for other tree species such as conifers, understory vegetations and their relative distribution in this heterogeneous and complex catchment area are largely unknown.

To examine the implications of the estimated $T$ for assessing carbon uptake capacity, we compared $T$ with wood biomass production (WBP) data in the Gwangneung catchment reported by Kim et al. (2010) since this is the only longterm productivity data in the study area. The WBP data were measured from 10 plots in the Gwangneung catchment with the size of each plot being $20 \mathrm{~m} \times 20 \mathrm{~m}$. The total number of measured tree specimen encompasses 259 from 17 species. In Fig. 5, there is an overall positive correlation between WBP and $T\left(r^{2}=0.44\right)$ with an exception in 2001. The relatively poor correlation is in part due to the difference in spatial scales (entire catchment vs. 10 selected plots within the catchment) and also indicates that other factors in addition to $T$ influenced WBP. The ratio of WBP (as $\mathrm{g} \mathrm{C} \mathrm{m}^{-2} \mathrm{y}^{-1}$ ) to $T$ (as $\mathrm{kg} \mathrm{H}_{2} \mathrm{O} \mathrm{m}^{-2} \mathrm{y}^{-1}$ ) ranged from 0.5 to 1.0. The ratio in general increases with decreasing $P$ and vice versa. The variable ratio (up to $100 \%$ ) signifies that the WUE may vary 


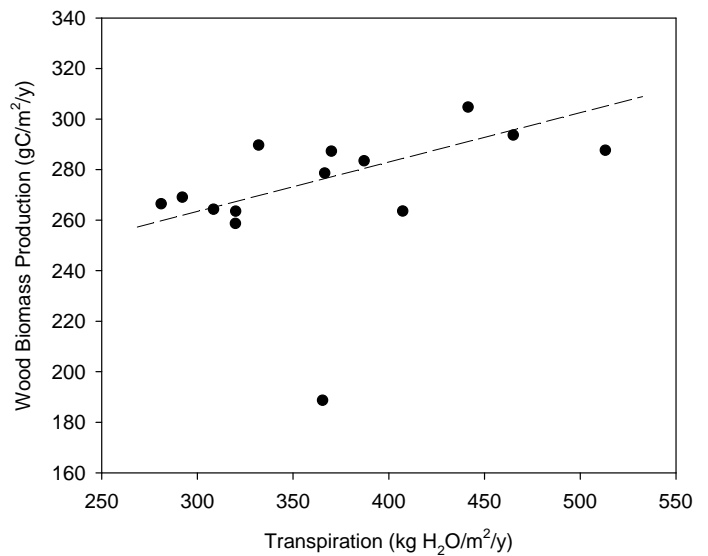

Fig. 5. The relationship between estimated $T$ and Wood Biomass Production (WBP) in the Gwangneung catchment from 1991 to 2005.

enough to compensate the change in $T$ and therefore the estimated $T$ alone is not enough to evaluate the carbon uptake capacity reliably unless the spatially representative $W U E$ is determined independently.

The magnitude and variability of $W U E$ was reviewed based on available information. In the Gwangneung catchment, GPP and ET data from the tower flux measurement were used to calculate catchment scale WUE from 2006 to 2008 (Kang et al., 2009; Kwon et al., 2010). The calculated

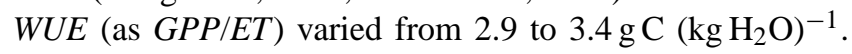
In eastern China, Yu et al. (2008) reported annual WUE (as $G P P / E T)$ from 1.9 to $2.6 \mathrm{~g} \mathrm{C}\left(\mathrm{kg} \mathrm{H}_{2} \mathrm{O}\right)^{-1}$ for diverse vegetation types under different climatic regimes. In the above WUE estimation, it should be noted that the contributions of $E_{S}$ and $E_{I}$ were not subtracted from $E T$.

The WUE estimates in terms of $G P P / T$ at ecosystem scale have been reported by Kuglitsch et al. (2008) for European forests based on eddy covariance flux measurement. Their annual WUE was $1.2( \pm 0.2) \mathrm{g} \mathrm{C}\left(\mathrm{kg} \mathrm{H}_{2} \mathrm{O}\right)^{-1}$ for temperate mixed forest and $1.4( \pm 0.2) \mathrm{gC}\left(\mathrm{kg} \mathrm{H}_{2} \mathrm{O}\right)^{-1}$ for temperate broad-leaved deciduous forests with $0.3 \sim 1.4 \mathrm{~g} \mathrm{C}$ $\left(\mathrm{kg} \mathrm{H}_{2} \mathrm{O}\right)^{-1}$ for all vegetation types. In their analyses, ET data after rainy days have been excluded to avoid the effect of intercepted evaporation. Based on biophysical considerations of $\mathrm{H}_{2} \mathrm{O}$ and $\mathrm{CO}_{2}$ exchanges in typical $\mathrm{C}_{3}$ plant leaves,

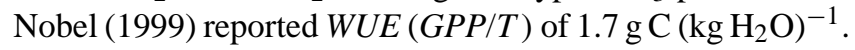

It is notable that the WUE estimates from East Asia discussed above are greater than those from European forests of comparable types. Considering that the estimates from East Asian forests were calculated from $E T$ without accounting for $E_{S}$ and $E_{I}$, the difference would become greater if $W U E$ is expressed as GPP/T. For Korean forests, the main cause of this discrepancy is likely due to the smaller forest $E T$ values estimated by both micrometeorological and hydrological water balance methods. The smaller ET in Korean forests is in part due to the concentrated precipitation during the summer monsoon period (typically July $\sim$ August). More than $\sim 50 \%$ of the annual rainfall occurs during this period (that rapidly discharges from the catchments) and a significant reduction in ET results from a substantial decrease in solar radiation (e.g., Kang et al., 2009). Since there are not many studies on $W U E$ for Korean forests, we do not have a clear answer for this discrepancy but speculate that WUE likely varies with climatological, hydrological, and ecological conditions.

At this stage, the derived $T$ cannot be used to estimate $G P P$ and its annual variation in the study area due to the lack of representative $W U E$ which is expected to vary with climatic conditions and vegetation types. For the terrestrial ecosystems in East Asia, natural and man-made disturbances (e.g., monsoon, drought, fire and management practices) significantly influence the coupling between carbon and water fluxes (e.g., Kwon et al., 2010). In this context, multinational collaborative studies are suggested to ascertain the magnitude, variability, and the controlling mechanisms of the ecosystem scale WUE. As the world's major greenhouse gas emission countries, China, Japan, and Korea initiated various cooperative activities to evaluate regional and continental scale carbon uptake capacity of the countries' terrestrial ecosystems, e.g., A3 Foresight "CarboEastAsia" program (http://www.carboeastasia.org). In relation to this pending scientific task, we present the approach based on catchment water budget as a practical and viable method to estimate spatially averaged annual carbon budget. Synthesis of hydrological and meteorological data will provide the long-term steady state water budget for major drainage basins in each country. Synthesis of eddy covariance tower flux measurements is currently underway through continental scale networks such as AsiaFlux (http://www.asiaflux.net), which will help understand the extent of biome-, climate-, physiology-, and disturbance-related effects on WUE. The work presented here on the Han River basin and its tributaries will serve as an exemplary study that awaits further improvement and applications.

\section{Summary and conclusions}

As an effort to understand the coupling between the water and carbon cycling in the Han River Basin and its tributaries, we attempted to partition $E T$ into its components based on hydrological, meteorological, and stable isotope data. Catchments of successive orders (spatial scales from $10^{0}$ to $10^{4} \mathrm{~km}^{2}$ ) were selected in the Han River basin, Korea as the study areas to examine a possible scale dependency of the hydrological processes under observation. Based on the stable isotope composition of $P$ and $Q$, the annual $E_{S}$ ranged from 0.3 to $2.3 \%$ of $P$ in the Han River basin without significant correlation with the catchment scales. The result indicates that $E T$ mostly comprised of $T$ and $E_{I}$ that are directly and indirectly related to plant productivity. From 1966 to $2007, T$ varied from 260 to $417 \mathrm{~mm} \mathrm{y}^{-1}$ or from 22 to $31 \%$ 
of the annual precipitation in the Han River basin as a whole. The estimated $T$, expressed as a simple function of $P$, can be used for assessing the carbon uptake capacity in terrestrial ecosystems, as an absolute measure if spatially representative $W U E$ is determined independently, or as a relative measure if the extent of variability in $W U E$ is constrained. Results from complementary carbon cycling studies in the Gwangneung catchment indicated that the annual change in $W U E$ could compensate the concurrent variation in $T$ and therefore the spatiotemporal variability of $W U E$ must be better understood to derive spatially representative GPP.

Acknowledgements. This study was supported by "CarboEastAsia - A3 Foresight Program" of National Research Foundation of Korea and a grant (Code: 1-8-3) from Sustainable Water Resources Research Center of 21st Century Frontier Research Program.

Edited by: J. Chen

\section{References}

Bates, B. C., Kundzewicz, Z. W., Wu, S., and Palutikof, J. P.: Climate Change and Water, Technical Paper of the Intergovernmental Panel on Climate Change, IPCC Secretariat, Geneva, 210 p., 2008.

Beer, C., Reichstein, M., Ciais, P., Farquhar, G. D., and Papale, D.: Mean annual GPP of Europe derived from its water balance, Geophys. Res. Lett., 34, L05401, doi:10.1029/2006GL029006, 2007.

Boughton, W. and Chiew, F.: Estimating runoff in ungauged catchments from rainfall, PET and the AWBM model, Environ. Modell. Softw., 22, 476-487, 2007.

Bryant M. L., Bhat, S., and Jacobs, J. M.: Measurements and modeling of throughfall variability for five forest communities in the southeastern US., J. Hydrol., 312, 95-108, 2005.

Chae, N., Lee, D., Lim, J.-H., Hong, J., and Kang, S.: Inferring Water and Carbon Exchanges from Leaf Carbon Isotope Composition of Quercus serrata and Carpinus laxiflora Grown in a Forest with a Complex Landscape in Korea, Asia-Pacific, J. Atmos. Sci., 45, 193-205, 2009.

Choi, S.-D., Lee, K., and Chang, Y.-S.: Large rate of uptake of atmospheric carbon dioxide by planted forest biomass in Korea, Global Biogeochem. Cy., 16(4), 1089, doi:10.1029/2002GB001914, 2002.

Choudhury, B. J.: Carbon-water-energy relations for selected river basins, Adv. Space Res., 26(7), 1091-1099, 2000.

Choudhury, B. J., DiGirolamo, N. E., Susskind, J., Darnell, W. L., Gupta, S. K., and Asrar, G.: A biophysical process-based estimate of global land surface evaporation using satellite and ancillary data, part II, Regional and global patterns of seasonal and annual variations, J. Hydrol., 205, 186-204, 1998.

Coplen, T. B. and Kendall, C.: Stable hydrogen and oxygen isotope ratios for selected sites of the U.S., Geological Survey's NASQAN and Benchmark Surface-water Networks, U.S. Geol. Surv., Open File Rep., 0-160, 2000.

Cuartas, L. A., Tomasella, J., Nobre, A. D., Hodnett, M. G., Waterloo, M. J., and Mu'nera, J. C.: Interception water-partitioning dynamics for a pristine rainforest in Central Amazonia: Marked differences between normal and dry years, Agr. Forest Meteorol., 145, 69-83, 2007.

de Groen, M. M. and Savenije, H. H. G.: A monthly interception equation based on the statistical characteristics of daily rainfall, Water Resour. Res., 42, W12417, doi:10.1029/2006WR005013, 2006.

Epstein, S. and Mayeda, T. K.: Variation of ${ }^{18} \mathrm{O}$ content of waters from natural sources, Geochim. Cosmochim. Ac. 4, 213-224, 1953.

Ferguson, P. R. and Veizer, J.: Coupling of water and carbon fluxes via the terrestrial biosphere and its significance to the Earth's climate system, J. Geophys. Res., 112, D24S06, doi:10.1029/2007JD008431, 2007.

Friedman, I. and O'Neil, J. R.: Compilation of stable isotope fractionation factors of geochemical interest, in Data of Geochemistry, Sixth Edition, Geological Survey Professional Paper, 440-KK, United States Government Printing Office, Washington, 1977.

Gash, J. H. C.: An analytical model of rainfall interception by forests, Q. J. R. Meteorol. Soc. 105, 43-55, 1979.

Gash, J. H. C., Lloyd, C. R., and Lachaud, G.: Estimating sparse forest rainfall interception with an analytical model, J. Hydrol., 170, 79-86, 1995.

Gat, J. R. and Bowser, C. J.: The heavy isotope enrichment of water in coupled evaporative systems, in: Stable Isotope Geochemistry: A Tribute to Samuel Epstein, edited by: Taylor Jr., H. P., O’Neil, J. R., and Kaplan, I. R., Geochemical Society Special Publications 3, 159-168, 1991.

Gat, J. R. and Matsui, E.: Atmospheric water balance in the Amazon Basin: An isotopic evapotranspiration model, J. Geophys. Res., 96, 13179-13188, 1991.

Gibson, J. J., Edwards, T. W. D., Bursey, G. G., and Prowse, T. D.: Estimating evaporation using stable isotopes: Quantitative results and sensitivity analysis for two catchments in North Canada, Nordic Hydrol., 24, 79-94, 1993.

Gibson, J. J., Edwards, W. D., and Prowse, T. D.: Development and validation of an isotopic method for estimating lake evaporation, Hydrol. Process., 10, 1369-1382, 1996.

Gibson, J. J. and Edwards, T. W. D.: Regional surface water balance and evaporation-transpiration partitioning from a stable isotope survey of lakes in northern Canada, Global Biogeochem. Cy.,16(2), doi:10.1029/2001GB001839, 2002.

Gonfiantini, R.: Environmental isotopes in lake studies, in: Handbook of Environmental Isotope Geochemistry, vol 2, Fritz, P. and Fontes, J. C., 113-168, Elsevier, New York, 1986.

Kang, M., Park, S., Kwon, H., Choi, H. T., Choi, Y.-J., and Kim, J.: Evapotranspiration from a deciduous forest in a complex terrain and a heterogeneous farmland under monsoon climate, AsiaPacific, J. Atmos. Sci., 45(2), 175-191, 2009.

Kim, J., Lee, D., Hong, J., et al.: HydroKorea and CarboKorea: cross-scale studies of ecohydrology and biogeochemistry in a heterogeneous and complex forest catchment of Korea, Ecol. Res., 21, 881-889, doi:10.1007/s11284-006-0055-3, 2006.

Kim, K., Jun, J., Yoo, J., and Jeong, Y.: Throughfall, stemflow and interception loss of the natural old-growth deciduous and planted young coniferous in Gwangneung and the rehabilitated young mixed forest in Yangju, Gyeonggido(I) - with a special reference on the results of measurement, J. Korean For. Res., (in Korean 
with English abstract), 94(6), 488-495, 2005.

Kim, S.-J., Lee, D., and Kim, S.: Use of Isotope Data to Determine Mean Residence Time (MRT) of Water in a Forest Catchment: ${ }^{35} \mathrm{~S}$ and ${ }^{3} \mathrm{H}$-based Estimates, Asia-Pacific, J. Atmos. Sci., 45, 165-173, 2009.

Kim, Y., Kang, S., Lim. J., Lee, D., and Kim, J.: Inter-annual and inter-plot variations of wood biomass production as related to biotic and abiotic characteristics at a deciduous forest in complex terrain, Korea, Ecol. Res., doi:10.1007/s11284-010-0705-3, 2010.

Kuglitsch, F. G., Reichstein, M., Beer, C., Carrara, A., Ceulemans, R., Granier, A., Janssens, I. A., Koestner, B., Lindroth, A., Loustau, D., Matteucci, G., Montagnani, L., Moors, E. J., Papale, D., Pilegaard, K., Rambal, S., Rebmann, C., Schulze, E. D., Seufert, G., Verbeeck, H., Vesala, T., Aubinet, M., Bernhofer, C., Foken, T., Grnwald, T., Heinesch, B., Kutsch, W., Laurila, T., Longdoz, B., Miglietta, F., Sanz, M. J., and Valentini, R.: Characterisation of ecosystem water-use efficiency of european forests from eddy covariance measurements, Biogeosciences Discuss., 5, 4481-4519, doi:10.5194/bgd-5-4481-2008, 2008.

Kwon, H., Kim, J., Hong, J., and Lim, J.-H.: Influence of the Asian monsoon on net ecosystem carbon exchange in two major ecosystems in Korea, Biogeosciences, 7, 1493-1504, doi:10.5194/bg-7-1493-2010, 2010.

Lee, D., Kim, J., Kim, S.-J., et al.: Lessons from Cross-Scale Studies of Water and Carbon Cycles in the Gwangneung Forest Catchment in a Complex Landscape of Monsoon Korea, Kor. J. Agric. Forest Meteor., 9(2), 149-160, 2007.

Lee, D. and Veizer, J.: Water and carbon cycles in the Mississippi River basin: Potential implications for the Northern Hemisphere residual terrestrial sink, Global Biogeochem. Cy., 17(2), 1037, doi:10.1029/2002GB001984, 2003.

Lee, K. S. and Lee, C. B.: Oxygen and hydrogen isotopic composition of precipitation and river waters in South Korea, J. Geol. Soc. Kor., (in Korean with English abstract), 35, 73-84, 1999

Milly, P. C. D., Betancourt, J., Falkenmark, M., Hirsch, R. M., Kundzewickz, Z. W., Lettenmaier, D. P., and Stouffer, R. J.: Stationarity is dead: Whither water management?, Science, 319, 573-574, 2008.

MOCT: Water Vision 2020 (in Korean), Ministry of Construction and Transportation, 147 pp., 2001.

Morrison, J., Brockwell, T., Merren, T., Fourel, F., and Phillips, A. M.: On-line high precision stable hydrogen isotopic analyses on nanoliter water samples, Anal. Chem., 73, 3570-3575, 2001.

Nobel, P.S.:Physicochemical and Environmental Plant Physiology, second edition, Academic Press, San Diego, 1999.
Rozanski, K., Araguás-Araguás, J., and Gonfiantini, R.: Isotopic patterns in modern global precipitation, in Climate Change in Continental Isotopic Records, edited by: Swart, P. K., Lohmann, K. C., McKenzie, J., and Savin, S., Geoph. Monog., 78, 1-36, 1993.

Slack, J. R., Lumb, A. M., and Landwehr, J. M.: U.S. Geological Survey Hydro-Climatic Data Network (HCDN): Streamflow Data Set, 1874-1988, USGS Open File Report 92-129, available at: http://pubs.usgs.gov/of/index-water.html, 1992.

Taylor, R.: Rethinking water scarcity: The role of storage, Eos, 90, 237-238, 2009.

Telmer, K. and Veizer, J.: Isotopic constraints on the transpiration, evaporation, energy and NPP budgets of a large boreal watershed: Ottawa River Basin, Canada, Global Biogeochem. Cy., 14, 149-165, 2000.

Telmer, K. and Veizer, J.: Correction to "Isotopic constraints on the transpiration, evaporation, energy and gross primary production budgets of a large boreal watershed: Ottawa River basin, Canada, Global Biogeochem. Cy., 15, 1035, doi:10.1029/2001GB001820, 2001

Tsujimura, M., Sasaki, L., Yamanaka, T., Sugimoto, A., Li, S.-G., Matsushima, D., Kotani, A., and Saandar, M.: Vertical distribution of stable isotopic composition in atmospheric water vapor and subsurface water in grassland and forest sites, eastern Mongolia, J. Hydrol., 333, 35-46, 2007.

Wang, X. and Yakir, D.: Using stable isotopes of water in evaporation studies, Hydrol. Process., 14, 1407-1421, 2000.

Williams, D. G., Cable, W., Hultine, K., Hoedjes, J. C. B., Yepez, E. A., Simonneaux, V., Er-Raki, S., Boulet, G., de Bruin, H. A R., Chehbouni, A., Hartogensis, O. K., and Timouk, F.: Components of evapotranspiration in an olive orchard determined by eddy covariance, sap flow and stable isotope techniques, Agric. For. Meteor., 125, 241-258, 2004.

Yepez, E. A., Williams, D. G., Scott, R. L., and Lin, G.: Partitioning overstory and understory evapotranspiration in a semiarid savanna woodland from the isotopic composition of water vapor., Agric. For. Meteor., 119, 53-68, 2003.

Yu, G., Song, X., Wang, Q., Liu, Y., Guan, D., Yan, J., Sun, X., Zhang, L., and Wen, X.: Water-use efficiency of forest ecosystems in eastern China and its relations to climatic variables, New Phytol., 177, 927-937, 2008.

Yu, J.-Y., Park, Y., Mielke, R. E., and Coleman, M. L.: Sulfur and oxygen isotopic compositions of the dissolved sulphate in the meteoric water in Chuncheon, Korea, Geosci. J., 11(4), 357-367, 2007. 